\title{
Equilibrium problems and fixed point theory
}

\author{
Qamrul Hasan Ansari ${ }^{1 *}$, Suliman Al-Homidan ${ }^{2}$ and Jen-Chih Yao ${ }^{3}$
}

* Correspondence: qhansari@gmail. com

${ }^{1}$ Department of Mathematics, Aligarh Muslim University, Aligarh 202 002, India

Full list of author information is available at the end of the article

\section{Equilibrium Problems and Fixed Point Theory}

The fixed point theory is a well-established subject in the area of nonlinear analysis. The iterative method for solving the fixed point problem was considered from the origin of this problem. Namely, Cauchy, Liouville, Lipschitz, Peano, Fredholm, Picard, Banach, Browder, Helpern, Mann, Ishikawa, etc., have given different kinds of iterative methods for solving fixed point problems.

The mathematical formulation of the equilibrium problem (EP) is to find an element $x$ of a set $K$ such that $f(x, y) \geq 0$ for all $y \in K$, where $f: K \times K \rightarrow \mathbb{R}$ be a bifunction. It is most general problem and includes many known problems, namely, variational inequality problem, optimization problem, saddle point problem, fixed point problem, Nash EP, etc., as special cases. This general form of EP was first considered by Nikaido and Isoda in 1955 as an auxiliary problem to establish existence results for Nash equilibrium points in non-cooperative games. In the theory of EPs, the key contribution was made by Ky Fan, whose new existence results contained the original techniques which became a basis for most further existence theorems in topological spaces.

This special issue contains 37 articles accepted on different topics in the area of fixed point theory and EPs. Ten articles are devoted to general fixed point theory, four are on iterative methods for solving variational inequalities, two on hierarchical variational inequalities, one is on some iterative methods for solving systems of variational inequalities, six are devoted to different kinds of iterative methods for solving EPs, seven are on iterative methods for systems of EP, and one is on the existence of solutions of system of generalized vector quasi-EPs. There are six more articles on different topics from nonlinear analysis.

Finally, we are grateful to Professor Ravi P. Agarwal and the publishers of the journal Fixed Point Theory and Applications for giving us the opportunity to edit this special issue.

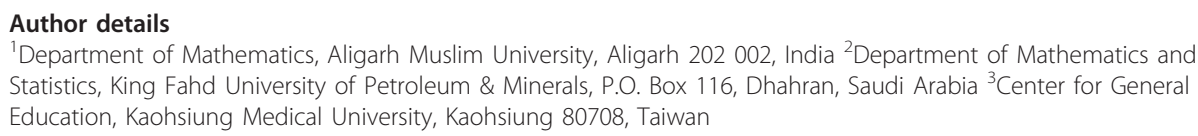

Received: 17 April 2011 Accepted: 24 February 2012 Published: 24 February 2012

doi:10.1186/1687-1812-2012-25

Cite this article as: Ansari et al.: Equilibrium problems and fixed point theory. Fixed Point Theory and Applications 2012 2012:25 